\title{
Life satisfaction mediates the association between childhood maltreatment and depressive symptoms: a study in a sample of Brazilian adolescents
}

\author{
Nina M. de Vasconcelos, ${ }^{1}$ iD Monica Ribeiro, ${ }^{2}$ Daniela Reis, ${ }^{1}$ Isabela Couto, ${ }^{1}$ Claudia Sena, ${ }^{1}$ \\ Ana C. Botelho, ${ }^{1}$ Dagoberto Bonavides, ${ }^{1}$ Curt Hemanny, ${ }^{1}$ Camila Seixas, ${ }^{1}$ Cristian P. Zeni, ${ }^{3}$ \\ Irismar R. de Oliveira ${ }^{1,2,3}$ \\ ${ }^{1}$ Programa de Pós-Graduação em Processos Interativos dos Órgãos e Sistemas, Instituto de Ciências da Saúde, Universidade Federal da \\ Bahia (UFBA), Salvador, BA, Brazil. ${ }^{2}$ Programa de Pós-Graduação em Medicina e Saúde, Faculdade de Medicina da Bahia, UFBA, Salvador, \\ BA, Brazil. ${ }^{3}$ School of Medicine, The University of Texas Health Science Center at Houston, Houston, TX, USA.
}

\begin{abstract}
Objective: To evaluate the interrelationships between childhood maltreatment, life satisfaction (LS), and depressive symptoms, and to investigate LS as a mediating factor in the association between childhood maltreatment and depressive symptoms.

Methods: The sample consisted of 342 adolescents, aged 11 to 17 years (mean $=13.3, \mathrm{SD}=1.52$ years), recruited from a public school in Salvador, Brazil. Participants filled out instruments for the collection of sociodemographic data and evaluation of childhood maltreatment, LS, and depressive symptoms. Structural equation modeling (SEM) was used to evaluate the mediating effect of LS.

Results: We detected significant negative correlations between childhood maltreatment and LS and between LS and depressive symptoms. We observed a significant positive correlation between childhood maltreatment and depressive symptoms. LS partially mediated the association between childhood maltreatment and depressive symptoms, mitigating the impact of maltreatment.

Conclusion: LS played an important mediating role in the association between childhood maltreatment and depressive symptoms. Longitudinal studies are recommended to fully elucidate these associations, reinforcing the need for attention and care of this vulnerable population.
\end{abstract}

Keywords: Adolescence; child maltreatment; personal satisfaction; depressive symptoms

\section{Introduction}

Life satisfaction (LS) is a subjective global judgment people make when they consider their life as a whole. ${ }^{1}$ Alongside positive and negative affect, it constitutes one of the facets of a wider construct known as subjective well-being. ${ }^{2}$ The negative association between LS and psychological disorders is well described in the literature ${ }^{3-6}$; for example, studies of children and adolescents have demonstrated negative associations between depressive symptoms and LS in their samples. ${ }^{7-9}$

In view of the variety of stressors that adolescents face during this period of life, such as biological changes, peer and academic pressures, and increasing independence from parents, ${ }^{10}$ LS in this population has become the object of growing research attention. ${ }^{7,11-15}$ Key to such research is the hypothesis that, in order to promote positive functioning in adolescence, one must not only gain insight into the typical problems of this phase of

Correspondence: Nina M. de Vasconcelos, Instituto de Ciências da Saúde, Universidade Federal da Bahia, Av. Reitor Miguel Calmon, $\mathrm{s} / \mathrm{n}^{\circ}, 4^{\circ}$ andar, sala 410 , Vale do Canela, CEP 40110-100, Salvador, BA, Brazil.

E-mail: ninamaiavas@ hotmail.com

Submitted May 01 2019, accepted Sep 11 2019, Epub Jan 242020. development but also focus on factors that may act as resources in how adolescents cope with adversities. ${ }^{9}$

Childhood maltreatment has been described in the literature as an important predictor of psychopathology. Many studies have demonstrated that experiencing abuse and neglect during childhood increases the likelihood of developing mental disorders in adult life. ${ }^{16-21}$ Yet, few studies have investigated possible psychological mediators between child maltreatment and mental disorders, ${ }^{22,23}$ especially those that could mitigate the negative effects of early experiences of abuse and neglect. ${ }^{24}$ Metel et al. ${ }^{22}$ found that resilience and cognitive biases partially mediate the relationship between early exposure to traumatic life events and depressive symptoms, and recent studies have demonstrated that social support mediates the effect of childhood maltreatment on mental health, ${ }^{24-27}$ but, as far as we know, no studies have investigated LS as a mediator in the relation between childhood maltreatment and mental disorders. 
Within this context, a cross-sectional study conducted in Norway by Moksnes et al. ${ }^{9}$ aimed to investigate the relationships between stressful school situations (school performance and interaction with teachers), LS, and depressive symptoms, as well as the potential mediating role of LS in the association of school stress and depressive symptoms. The results showed moderate to strong associations between the three variables studied. School stress correlated positively with depressive symptoms and inversely with LS, which has been shown to mediate, albeit partially, the association between school performance-related stress and depressive symptoms. ${ }^{9}$

A study by Veronese et al. ${ }^{28}$ aimed to evaluate the interrelationships between LS, balance of affects, and trauma symptoms in a sample of 1,276 Palestinian children (mean $[\mathrm{M}]=8.8$ years old) who lived in a war context and attended schools located in refugee camps. The data showed that higher levels of LS contributed to a better balance of positive affects in children, which in turn helped mitigate the effects of exposure to trauma. These findings led the authors to conclude that LS helped children soften their negative emotions, promote positive affects, and exhibit fewer trauma-related symptoms, such as avoidance and intrusive thoughts. The researchers also concluded that individual and contextual factors that bring satisfaction to life, such as self-satisfaction, satisfaction with peers, with family, with school, and with living conditions, together with the ability to activate positive emotions, are key factors in subjective well-being and in the capacity to cope with traumatic situations. ${ }^{28}$

These two studies demonstrated that individuals who were more satisfied with life were also less likely to develop psychopathological symptoms, as LS operates as a protective psychological strength that provides a buffer against the effects of adverse life events. ${ }^{29}$ Considering that research has demonstrated that abuse and neglect during childhood increase the likelihood of later development of mental disorders, ${ }^{16-21}$ the present study aimed to investigate how three variables - childhood maltreatment, LS, and depressive symptoms - are related and whether LS could be a mediator in the relationship between them, mitigating the effects of maltreatment by buffering the presentation of depressive symptoms in adolescence. Four hypotheses were considered, based on the existing literature (Figure 1):

- H1: childhood maltreatment correlates negatively with LS;

- H2: LS correlates negatively with depressive symptoms;

- H3: maltreatment in childhood correlates positively with depressive symptoms;

- H4: LS is a mediator in the association between maltreatment and depressive symptoms.

\section{Methods}

\section{Sample}

The sample comprised 342 adolescents (age 11 to 17 years) who attended a municipal public school in the

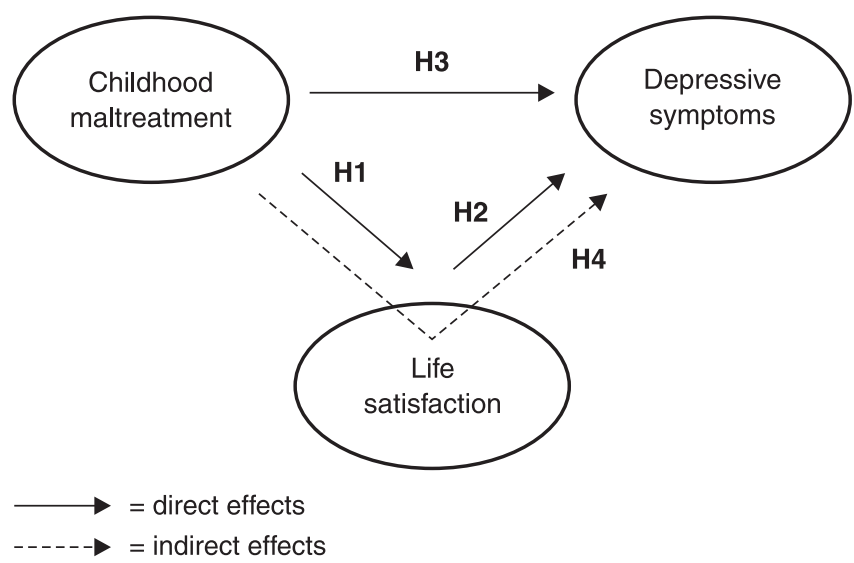

Figure 1 Hypotheses $(H)$ to be verified in this study.

city of Salvador, state of Bahia, Brazil. This school is located in a neighborhood with serious social problems, which include drug trafficking, violence, and a limited public safety presence. Moreover, the school has poor infrastructure, restricted physical space with a limited leisure and sports area, and frequent teacher strikes - factors that may interfere within adolescents' learning and quality of life. Most families received welfare support in the form of the Bolsa Familia (Family Fund) conditional cash transfer program. A more detailed description of this sample has been published elsewhere. ${ }^{21}$

\section{Procedure}

This study was conducted as a part of a larger research project designed to assess the efficacy of the Group TrialBased Cognitive Training (G-TBCT) program, ${ }^{30}$ which aims to prevent anxiety disorders and depression in adolescents. Data were collected during the first and the second school semesters of 2015. First, the Municipal Department of Education in Salvador was contacted and asked to nominate a school to participate in the study. Then, the project was presented to the principal and faculty of the selected school. Finally, the students' parents were invited to learn more about the project at a meeting, which lasted approximately 50 minutes. Parents who were unable to attend the meeting were contacted and the project was explained to them individually or in small groups on alternate dates. Those parents or guardians who agreed to the participation of their children signed a consent form, while adolescents signed an assent form.

\section{Measures}

\section{Children's Depression Inventory (CDI)}

This instrument consists of an adaptation of the Beck Depression Inventory (BDI), originally designed for adults. It is widely used in research involving childhood depression and its purpose is to detect the presence and level of severity of depressive symptoms in children and adolescents between 7 and 17 years of age. ${ }^{31}$ 
The original CDI consists of 27 items that assess cognitive, emotional, somatic, and behavioral symptoms. For each item, there are three alternatives, and the respondent is asked to choose the alternative that best describes his or her symptoms. The Brazilian version of the CDI had the number of items reduced to 20 , and is scored on a threepoint Likert scale that generates a dimensional score ranging from 0 to 40 . A higher score denotes more severe depressive symptoms. The CDI was adapted for use in the country by Gouveia et al. ${ }^{32}$ in a sample of 305 children and adolescents, aged 8 to 15 years, recruited from public and private schools. The results of the Brazilian sample confirmed the instrument's unifactorial structure, with factor loadings higher than 0.35 , an internal consistency of 0.81 , eigenvalue of 3.73 , and explained variance equal to $13.5 \%$. The cutoff point was 17, indicating that respondents with a score of 17 or higher might have a depressive disorder.

\section{Childhood Trauma Questionnaire (CTQ)}

This instrument is designed to evaluate childhood maltreatment in adolescents and adults. It is composed of 28 items across five subscales: physical abuse, emotional abuse, sexual abuse, physical neglect, and emotional neglect, scored on a five-point Likert scale (ranging from never true to very often true). The points scored on each item are added, with scores ranging from 5 to 25 for each of the subscales. ${ }^{33}$ In the present study, the Cronbach coefficients identified were: 0.31 for physical neglect; 0.61 for physical abuse; 0.68 for sexual abuse; 0.74 for emotional neglect; and 0.78 for emotional abuse.

\section{Multidimensional Student Life Satisfaction Scale (MSLSS)}

The MSLSS was developed to demonstrate the LS profile of children and adolescents in five specific domains: school satisfaction, family satisfaction, satisfaction with friends, satisfaction with living environment, and self-satisfaction. The MSLSS consists of 40 items scored on a Likert scale from 1 to 6 . A total score and subscores for the five abovementioned subscales were generated by adding the specific items. According to Gilman \& Huebner, ${ }^{10}$ the use of multidimensional instruments such as MSLSS allows greater sensitivity to possible differences in LS in specific domains that could be masked by exclusively global evaluations. It should be emphasized, however, that the global level of LS can also be obtained by this instrument by adding the values found for each subscale.

MSLSS was adapted to the Brazilian culture in a study conducted by Barros et al., ${ }^{34}$ in a sample of 49 students, aged 12 to 18 , recruited from two schools (one public, one private). The authors found an internal consistency of 0.88 for the public school and 0.79 for the private school. Comparative analyses of the Cronbach coefficient for the five domains showed that the instrument has a high level of reliability and is therefore a good option to evaluate LS among Brazilian adolescents.

\section{Statistical analysis}

The goal of our study was to evaluate the interaction between quantitative aspects of depressive symptoms, childhood maltreatment, and LS. Thus, no cutoff point scores were considered, and no dichotomous variables created. To test for direct associations between the variables of interest, Pearson correlation coefficients ( $r$ ) were calculated. Associations with a Pearson's $r$ between 0 and 0.19 were considered very weak; between 0.20 and 0.39 , weak; between 0.40 and 0.59 , moderate; between 0.60 and 0.79 , strong; and between 0.80 and 1.00 , very strong.

The mediating role of LS in the association between childhood maltreatment and depressive symptoms $(\mathrm{H} 4)$ was tested using structural equation modeling (SEM). A variable is considered a mediator when it can influence the association between a predictor variable and the dependent variable. The following conditions are required for a variable to exert a complete mediation function: 1) changes in the independent variable have significant influence on the presumed mediating variable (path a); 2) variations in the presumed mediator variable have significant influence on the dependent variable (path b); and (3) when paths $a$ and $b$ are considered together, the direct relationship between the independent variable and the dependent variable (path $\mathrm{c}$ ) is no longer statistically significant. ${ }^{35}$

In the present study, depressive symptoms were considered the dependent variable, whereas maltreatment and LS were both considered independent variables. It is important to note that LS was also tested as a mediator variable. The MSLSS (LS) scores and the CTQ (maltreatment) scores were analyzed in their general forms and in their specific domains: family satisfaction, satisfaction with friendships, satisfaction with the living environment, self-satisfaction, and school satisfaction for the MSLSS; and physical abuse, emotional abuse, sexual abuse, and physical and emotional neglects for CTQ.

\section{Ethics statement}

This study was approved by the institutional review board of Maternidade Climério de Oliveira, Universidade Federal da Bahia. All parents/guardians of the participants provided written informed consent, while the adolescents themselves signed an assent form.

\section{Results}

Of the 342 participants, $52.92 \%$ were male; the mean age was 13.3 years. The sample was ethnically diverse (45.91\% black, $36.84 \%$ mixed, $9.06 \%$ white, $4.39 \%$ Asian, and $3.80 \%$ Amerindian).

The mean CDI score was 5.94. Overall satisfaction presented an average of 4.63 , and the average found for maltreatment (overall) was 44.68. Table 1 summarizes the means and standard deviations (SD) for depressive symptoms, LS (global and specific), and childhood maltreatment (global and specific). Only $7.30 \%$ of the sample had a CDI score of 17 or greater, which means that the vast majority of respondents did not have significant depressive symptomatology. According to the CTQ, emotional neglect was the most frequent type of maltreatment exposure, followed by physical neglect, emotional 
abuse, physical abuse, and sexual abuse. The frequency of maltreatment exposure is presented in Table 2.

Most of the variables of interest were correlated; only the associations between physical neglect and school satisfaction, and between physical neglect and environment satisfaction, were not significant. The correlation level between the variables ranged from weak to strong for all significant associations, the lowest one being observed in the association between satisfaction with living environment and sexual abuse (Pearson's $r=$ 0.114 ), and the highest between overall LS and depressive symptoms (Pearson's $r=0.637$ ). It should be noted that all correlations occurred in the expected directions: maltreatment correlated positively with depressive symptoms and inversely with LS, and depressive symptoms were inversely correlated with LS. Table 3 summarizes the correlations between childhood maltreatment, LS, and depressive symptoms.

In order to evaluate the mediating effect of LS on the association between childhood maltreatment and depressive symptoms, 11 models were tested through SEM:

- Model 1 tested the overall mediation of LS in the association between maltreatment and depressive symptoms;

- Models 2 to 6 tested the mediation of LS for different types of maltreatment and depressive symptoms;

- Models 7 to 11 tested the mediation by specific domains of LS between maltreatment and depressive symptoms.

It should be emphasized that SEM was applied to test those correlations whose variables demonstrated a linear

Table 1 Scores (mean and standard deviation) obtained for depressive symptoms, life satisfaction, and maltreatment

\begin{tabular}{lc}
\hline Variable & \\
\hline Depressive symptoms & $5.94(5.73)$ \\
Life satisfaction (global) & $4.63(0.73)$ \\
Life satisfaction & $4.75(1.15)$ \\
Friendship satisfaction & $4.90(0.84)$ \\
School satisfaction & $4.52(1.05)$ \\
Environment satisfaction & $4.09(0.97)$ \\
Self-satisfaction & $5.11(1.05)$ \\
& \\
Maltreatment (global) & $44.68(11.63)$ \\
Physical neglect & $7.20(2.73)$ \\
Emotional neglect & $10.04(4.99)$ \\
Sexual abuse & $5.32(1.36)$ \\
Physical abuse & $6.15(2.15)$ \\
Emotional abuse & $8.27(4.07)$ \\
\hline
\end{tabular}

pattern of association, which is an essential condition for its use. ${ }^{36}$

In models 1 to 6 , the beta values were significant for the totality of the direct associations. In models 1, 2, 3, and 4, there were partial mediations of LS in the association between childhood maltreatment and depressive symptoms. Models 5 and 6 demonstrated total mediations of LS in the association between both emotional and physical neglect and depressive symptoms. Mediations were considered total in these models since, in addition to the large reduction observed in the beta values, the inclusion of the LS variable in the models made the direct association between the two types of neglect and depressive symptoms not statistically significant.

Data for models 1 to 6 (including beta values, p-values, and type of mediation observed) are presented in Table 4. Figure 2 demonstrates model 1.

Models 7 to 11 tested the mediation by specific domains of LS between maltreatment and depressive symptoms. In all these models, beta values were significant for the direct associations between maltreatment and depressive symptoms, as well as for the direct associations between each LS domain and depressive symptoms. Partial mediations of LS domains were observed in the association between maltreatment and depressive symptoms in all models. Data referring to models 7 to 11 are presented in Table 5 .

\section{Discussion}

The present study aimed to investigate the relationships between childhood maltreatment, LS, and depressive symptoms, as well as the mediating role of LS in the association between maltreatment and depression symptoms. Four hypotheses were tested: $\mathrm{H} 1$, that childhood maltreatment correlates negatively with LS; H2, that LS correlates negatively with depressive symptoms; $\mathrm{H} 3$, that childhood maltreatment correlates positively with depressive symptoms; and H4, that LS is a mediator in the association between maltreatment and depressive symptoms.

In agreement with the first hypothesis (H1), the results indicated a negative, significant, and moderate correlation between maltreatment (overall) and LS (overall). LS (overall) was significantly correlated, albeit weakly to moderately, with all types of maltreatment. The correlation between LS (overall) and emotional abuse was the strongest among the associations between LS (overall) and the five types of maltreatment investigated. The correlation between family satisfaction and maltreatment

Table 2 Frequency of maltreatment exposure $(n=342)$

\begin{tabular}{|c|c|c|c|c|}
\hline \multirow[b]{2}{*}{ Maltreatment type* } & \multicolumn{4}{|c|}{ CTQ threshold } \\
\hline & None & Low & Moderate & Severe \\
\hline Emotional abuse & $220(64.3)$ & $69(20.2)$ & $27(7.9)$ & $26(7.6)$ \\
\hline Physical abuse & 291 (85.1) & $27(7.9)$ & $15(4.4)$ & $9(2.6)$ \\
\hline Sexual abuse & $306(89.5)$ & $17(5.0)$ & $17(5.0)$ & $2(0.6)$ \\
\hline Emotional neglect & $189(55.3)$ & $87(25.4)$ & $33(9.6)$ & $33(9.6)$ \\
\hline Physical neglect & $205(59.9)$ & $82(24.0)$ & 37 (10.8) & $18(5.3)$ \\
\hline
\end{tabular}

Data presented as $\mathrm{n}(\%)$.

* Proportion of students who are classified as having experienced none, low, moderate, or severe maltreatment based on Childhood Trauma Questionnaire (CTQ) thresholds. 
Table 3 Correlations between childhood maltreatment, life satisfaction, and depressive symptoms

\begin{tabular}{|c|c|c|c|c|c|c|c|}
\hline & $\begin{array}{c}\text { Childhood } \\
\text { maltreatment (total) }\end{array}$ & $\begin{array}{l}\text { Physical } \\
\text { abuse }\end{array}$ & $\begin{array}{l}\text { Emotional } \\
\text { abuse }\end{array}$ & $\begin{array}{l}\text { Sexual } \\
\text { abuse }\end{array}$ & $\begin{array}{c}\text { Physical } \\
\text { neglect }\end{array}$ & $\begin{array}{c}\text { Emotional } \\
\text { neglect }\end{array}$ & $\begin{array}{l}\text { Depressive } \\
\text { symptoms }\end{array}$ \\
\hline \multicolumn{8}{|c|}{ Depressive symptoms } \\
\hline Pearson's $r$ & $0.56^{*}$ & $0.43^{*}$ & $0.56^{*}$ & $0.38^{*}$ & $0.18^{*}$ & $0.32 *$ & 1 \\
\hline p-value & 0.00 & 0.00 & 0.00 & 0.00 & 0.00 & 0.00 & \\
\hline $\mathrm{n}$ & 342 & 342 & 342 & 342 & 342 & 342 & 343 \\
\hline \multicolumn{8}{|c|}{ Life satisfaction (global) } \\
\hline Pearson's $r$ & $-0.59 *$ & $-0.38 *$ & $0.49 *$ & $-0.26 *$ & $-0.22 *$ & $-0.42^{*}$ & $-0.64 *$ \\
\hline$p$-value & 0.00 & 0.00 & 0.00 & 0.00 & 0.00 & 0.00 & 0.00 \\
\hline $\mathrm{n}$ & 342 & 342 & 342 & 342 & 342 & 342 & 342 \\
\hline \multicolumn{8}{|c|}{ Family satisfaction } \\
\hline Pearson's $r$ & $-0.63^{*}$ & $-0.39 *$ & $-0.51 *$ & $-0.17 *$ & $-0.24 *$ & $-0.49 *$ & $-0.58 *$ \\
\hline$p$-value & 0.00 & 0.00 & 0.00 & 0.001 & 0.00 & 0.00 & 0.00 \\
\hline$n$ & 342 & 342 & 342 & 342 & 342 & 342 & 342 \\
\hline \multicolumn{8}{|c|}{ Friendship satisfaction } \\
\hline Pearson's $r$ & $-0.44 *$ & $-0.26 *$ & $-0.33^{*}$ & $-0.20 *$ & $-0.21 *$ & $-0.33^{*}$ & $-0.42 *$ \\
\hline$p$-value & 0.00 & 0.00 & 0.00 & 0.00 & 0.00 & 0.00 & 0.00 \\
\hline$n$ & 342 & 342 & 342 & 342 & 342 & 342 & 342 \\
\hline \multicolumn{8}{|c|}{ School satisfaction } \\
\hline Pearson's $r$ & $-0.28 *$ & $-0.25^{*}$ & $-0.24 *$ & $-0.20 *$ & -0.07 & $-0.17^{*}$ & $-0.39 *$ \\
\hline p-value & 0.00 & 0.00 & 0.00 & 0.00 & 0.18 & 0.00 & 0.00 \\
\hline $\mathrm{n}$ & 342 & 342 & 342 & 342 & 342 & 342 & 342 \\
\hline \multicolumn{8}{|c|}{ Living environment satisfaction } \\
\hline Pearson's $r$ & $-0.35^{*}$ & $-0.21^{*}$ & $-0.38 *$ & $-0.11^{\dagger}$ & -0.09 & $-0.23^{*}$ & $-0.38 *$ \\
\hline$p$-value & 0.00 & 0.00 & 0.00 & 0.03 & 0.11 & 0.00 & 0.00 \\
\hline $\mathrm{n}$ & 342 & 342 & 342 & 342 & 342 & 342 & 342 \\
\hline \multicolumn{8}{|l|}{ Self-satisfaction } \\
\hline Pearson's $r$ & $-0.43^{*}$ & $-0.27^{*}$ & $-0.25^{*}$ & $-0.25^{*}$ & $-0.24^{*}$ & $-0.34^{*}$ & $-0.54 *$ \\
\hline$p$-value & 0.00 & 0.00 & 0.00 & 0.00 & 0.00 & 0.00 & 0.00 \\
\hline $\mathrm{n}$ & 342 & 342 & 342 & 342 & 342 & 342 & 342 \\
\hline
\end{tabular}

Data presented as Pearson's $r, p$-value, and $n$.

* Significant correlation at the 0.01 level (two-tailed).

'Significant correlation at the 0.05 level (two-tailed).

\begin{tabular}{|c|c|c|c|c|c|c|c|c|}
\hline & \multirow[b]{2}{*}{ Correlation } & \multirow{2}{*}{$\begin{array}{c}\text { Prior } \\
\text { standardized } \\
\text { beta }\end{array}$} & \multirow[b]{2}{*}{$p$-value } & \multirow{2}{*}{$\begin{array}{c}\text { Posterior } \\
\text { standardized } \\
\text { beta }\end{array}$} & \multirow[b]{2}{*}{$p$-value } & \multirow{2}{*}{$\begin{array}{c}\text { Posterior } \\
\text { standardized } \\
\text { beta - LS }\end{array}$} & \multicolumn{2}{|c|}{ Mediation type } \\
\hline & & & & & & & Total & Partial \\
\hline Maltreatment (total) & 0.56 & 0.56 & 0.000 & 0.28 & 0.000 & -0.48 & & $x$ \\
\hline Emotional abuse & 0.56 & 0.56 & 0.000 & 0.33 & 0.000 & -0.48 & & $x$ \\
\hline Physical abuse & 0.43 & 0.43 & 0.000 & 0.22 & 0.000 & -0.55 & & $\mathrm{x}$ \\
\hline Sexual abuse & 0.38 & 0.38 & 0.000 & 0.23 & 0.000 & -0.58 & & $x$ \\
\hline Emotional neglect & 0.32 & 0.32 & 0.000 & 0.06 & 0.17 & -0.61 & $x$ & \\
\hline Physical neglect & 0.18 & 0.18 & 0.001 & 0.04 & 0.34 & -0.63 & $\mathrm{x}$ & \\
\hline
\end{tabular}

(CTQ overall) was the strongest. This finding may denote persisting maltreatment, or be indicative of the consequences of childhood abuse and neglect in current family relationships. The associations between satisfaction with school and physical neglect, and between satisfaction with the living environment and physical neglect, were the only ones that were not significant among those surveyed, which means that being a victim of physical neglect is not associated with the way that the adolescents in the sample evaluated their satisfaction with school or their living environment. It should be noted that the internal consistency for the physical neglect subscale of the CTQ in the present study was low, which suggests that these data should be interpreted carefully.

The second hypothesis ( $\mathrm{H} 2)$ was also confirmed; the data showed a strong, significant, and negative correlation of LS (overall) with depressive symptoms. These findings are in agreement with other studies of children and adolescents, which demonstrated the negative association between LS and depression..$^{7-9}$ Regarding $\mathrm{H} 2$, it is also worth noting that all LS domains correlated negatively with the depressive symptoms. Family satisfaction, 


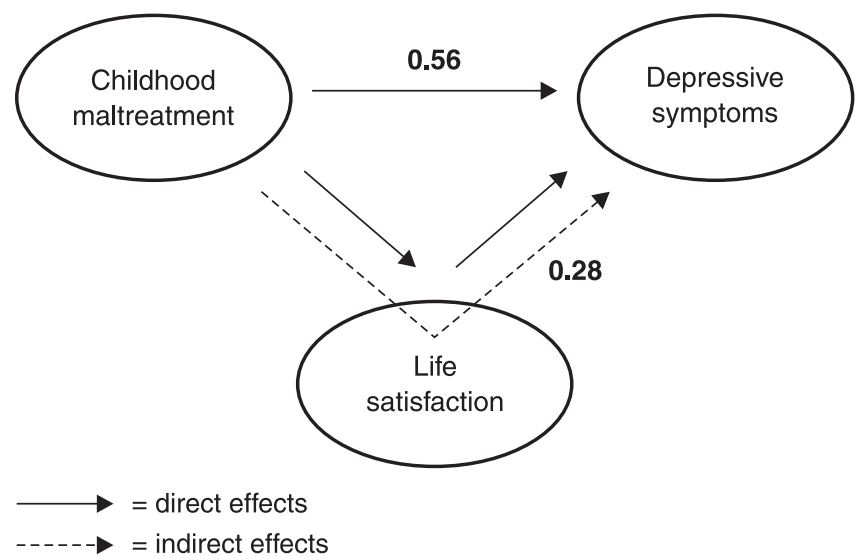

Figure 2 Model 1 demonstrating the partial mediation of life satisfaction (overall) in the association between maltreatment and depressive symptoms.

followed by self-satisfaction, were the LS domains most strongly associated with depressive symptoms. The fact that family satisfaction had the strongest correlation with depressive symptoms highlights the importance of family relationships to adolescent mental health.

The third hypothesis (H3) was also confirmed; according to our results, childhood maltreatment correlated moderately and positively with depressive symptoms. These findings are in agreement with studies that have evaluated the association between maltreatment and the development of psychopathologies, and the presence of internalizing as well as externalizing symptoms. ${ }^{16-21,37-43}$ It should be emphasized that, among the types of maltreatment surveyed, emotional abuse was that most strongly associated with depressive symptoms. This finding is in agreement with previous studies by Bifulco et al., ${ }^{16}$ which concluded in favor of a strong association between childhood emotional abuse and development of depression in adulthood, and Cecil et al., ${ }^{20}$ which detected greater negative effects on the mental health of victims of emotional abuse.

The results also confirmed the fourth hypothesis $(\mathrm{H} 4)$, which was tested through the development of 11 models. Model 1 tested the mediation of LS (overall) on the association between maltreatment (overall) and depressive symptoms. The beta values found demonstrated a partial mediation of LS in this association. These findings are in line with the hypothesis that those individuals who are more satisfied with life are less likely to develop psychopathological symptoms when faced with adversity. ${ }^{29}$
Thus, although childhood maltreatment correlated positively with depressive symptoms, analysis of these models suggests that being more satisfied with life may mitigate the effect of such maltreatment with respect to the manifestation of depressive symptoms.

In this context, the studies by Veronese et al. ${ }^{28}$ and Moksnes et al. ${ }^{9}$ are again worth noting. In their research with Palestinian children living in a war context, Veronese et al. $^{28}$ concluded that LS helped children reduce symptoms related to trauma. In turn, Moksnes et al. ${ }^{9}$ demonstrated, in their research with students, that LS partially mediated the association between school stress and depressive symptoms. Although the aforementioned studies do not refer to traumas suffered in childhood, but rather to current adversities, both demonstrate that LS is an important indicator of subjective well-being and, as the present study also demonstrated, can exert an attenuating role in the manifestation of depressive symptoms.

Models 2, 3, and 4 evaluated the mediating role of LS in the association between emotional, physical, and sexual abuse (respectively) and depressive symptoms. As in model 1, a partial mediation of the LS variable was verified in these three models; this is in line with the concepts of Baron \& Kenny. ${ }^{35}$ According to these authors, since the phenomena studied by psychological science are complex and multifactorial, it is more realistic to find mediators that do not eliminate the impact of the variable predictor in the dependent variable, but attenuate its effect.

Models 5 and 6 evaluated the mediating effect of LS on the association between emotional and physical neglect, respectively, and depressive symptoms. In these models, total LS mediation was verified, i.e., after inclusion of the LS mediator variable, the direct associations of physical and emotional neglects with depressive symptoms were no longer statistically significant. The total mediation of LS in the association between emotional neglect and depressive symptoms found in this sample evinces the relevant role that LS can play in the mental health of adolescents; even deprivation of emotional attention during childhood may not have an impact on the development of depressive symptoms, provided that the individual feels satisfied with his or her life.

Concerning the total mediation of LS in the association between physical neglect and depressive symptoms, it should be noted, once again, that the physical neglect subscale presented low internal consistency; caution is thus advised when interpreting this finding. It is also important to consider that, due to the low socioeconomic level of our sample, it is possible that physical neglect

Table 5 Mediation of specific life satisfaction (LS) domains in the association between maltreatment and depressive symptoms (models 7 to 11 )

\begin{tabular}{|c|c|c|c|c|c|c|c|c|}
\hline & \multirow[b]{2}{*}{ Correlation } & \multirow{2}{*}{$\begin{array}{c}\text { Prior } \\
\text { standardized } \\
\text { beta }\end{array}$} & \multirow[b]{2}{*}{$p$-value } & \multirow{2}{*}{$\begin{array}{c}\text { Posterior } \\
\text { standardized } \\
\text { beta }\end{array}$} & \multirow[b]{2}{*}{$\mathrm{p}$-value } & \multirow{2}{*}{$\begin{array}{c}\text { Posterior } \\
\text { standardized } \\
\text { beta - LS }\end{array}$} & \multicolumn{2}{|c|}{ Mediation type } \\
\hline & & & & & & & Total & Partial \\
\hline Family satisfaction & -0.63 & 0.56 & 0.00 & 0.32 & 0.00 & -0.37 & & $x$ \\
\hline Friendship satisfaction & -0.44 & 0.56 & 0.00 & 0.46 & 0.00 & -0.22 & & $\mathrm{x}$ \\
\hline School satisfaction & -0.28 & 0.56 & 0.00 & 0.48 & 0.00 & -0.25 & & $\mathrm{x}$ \\
\hline Living environment satisfaction & -0.35 & 0.56 & 0.00 & 0.48 & 0.00 & -0.21 & & $\mathrm{x}$ \\
\hline Self-satisfaction & -0.43 & 0.56 & 0.00 & 0.40 & 0.00 & -0.36 & & $x$ \\
\hline
\end{tabular}


evaluated by CTQ through questions such as " 1 . I did not have enough to eat" and " 6 . I had to wear dirty clothes" might be more due to financial difficulties than with intentional deprivation and the perception associated with the latter.

Models 7 to 11 evaluated, respectively, the mediating role of the variables family satisfaction, satisfaction with friendships, satisfaction with school, satisfaction with living environment, and self-satisfaction in the association between maltreatment and depressive symptoms. In all of these models, partial mediations were observed, with family satisfaction having the greatest mediation effect. This finding shows the important ongoing role that the family plays in the emotional health of adolescents, indicating that it can be possible, through positive family relationships, to mitigate the effects of negative experiences in childhood. It bears stressing that the mediating effect of self-satisfaction also stood out among the others domains of LS, which indicates the importance of promoting adolescents' self-esteem.

Adolescence is a very important stage of the life course, since, among other factors, it is during this period that the bases for health are built. ${ }^{44}$ Identifying the mediating role that LS can exert in adolescents' mental health, as demonstrated in this study, is of great relevance. The finding that greater LS may attenuate depressive symptoms related to childhood maltreatment is very promising. Such a finding may be useful for the development of public policies improving LS for adolescents, especially for those who have been abused or neglected.

Several limitations of the present study should be considered. First, the use of cross-sectional data means that the associations found herein might have been biased by the fact that measurements were obtained at the same time. For example, the evaluation of LS may have been influenced by depressive symptoms, as those adolescents with depressive symptoms, through a cognitive bias, may have a worse perception of their lives than do adolescents with no symptoms. Longitudinal studies are needed to elucidate these associations. All the variables of interest were rated only by the adolescents themselves, which creates a further risk of bias. Data were collected in only one public school; considering that many differences exist between public and private educational facilities in Brazil, our sample would ideally have included students from private schools and from more than one public school. The physical neglect subscale of the CTQ instrument had low internal consistency (Cronbach's alpha $=3.1$ ), which means data measured by this instrument should be interpreted with caution.

These findings have important implications for clinical practice in mental health, for research into risk and protective factors, and for the development of public policies. Concerning clinical practice, the present study highlights the importance of screening for maltreatment during childhood, as it increases the odds of developing depressive symptoms; in terms of intervention, it suggests that strategies that promote satisfactory family relationships (such as development of parenting skills) and self-satisfaction should be prioritized. Concerning research, this study reinforces the importance of knowing which factors may mitigate the effects of adversities. Further research is warranted to learn more about these factors. Finally, our findings have very important implications for the development of public policies. Since this study has demonstrated that the effects of maltreatment can be attenuated through positive LS, it is paramount that adolescents be offered a good education and an enabling environment with good infrastructure, health, and public safety. On the other hand, it should be noted that, as individual perceptions of LS also depend on psychological factors, prevention and intervention programs for adolescents' mental health may be a key strategy to help this population develop a healthy selfesteem and positive family and social interactions. Thus, it is strongly suggested that such programs be offered in schools.

\section{Acknowledgements}

We thank the staff and teachers at Escola Municipal Visconde de Cairu (Salvador, Brazil) for their support, as well as Jones Aranha de Sá and Juliano Matos, who made this study possible by introducing the authors to the Salvador Municipal Department of Education.

\section{Disclosure}

The authors report no conflicts of interest.

\section{References}

1 Diener ED, Suh EM, Lucas RE, Smith HL. Assessing subjective wellbeing: progress and opportunities. Soc Indic Res. 1994;31:103-57.

2 Diener ED, Suh EM, Lucas RE, Smith HL. Subjective well-being: three decades of progress. Psychol Bull. 1999;125:276-302.

3 Collins AM, Glei DA, Goldman N. The role of life satisfaction and depressive symptoms in all-cause mortality. Psychol Aging. 2009;24: 696-702.

4 Daig I, Herschbach P, Lehmann A, Knoll N, Decker O. Gender and age differences in domain-specific life satisfaction and the impact of depressive and anxiety symptoms: a general population survey from Germany. Qual Life Res. 2009;18:669-78.

5 Serin NB, Serin O, Özbas LF. Predicting university students' life satisfaction by their anxiety and depression level. Procedia Soc Behav Sci. 2010;9:579-82.

6 Nes RB, Czajkowski NO, Røysamb E, Orstavik RE, Tambs K, Reichborn-Kjennerud T. Major depression and life satisfaction: a population-based twin study. J Affect Disord. 2013;144:51-8.

7 Gilman R, Huebner ES. Characteristics of adolescents who report very high life satisfaction. J Youth Adolesc. 2006;35:293-301.

8 Stankov L. Depression and life satisfaction among European and Confucian adolescents. Psychol Assess. 2013;25:1220-34.

9 Moksnes UK, Lohre A, Lillefjell M, Byrne DG, Haugan G. The association between school stress, life satisfaction and depressive symptoms in adolescents: life satisfaction as a potential mediator. Soc Indic Res. 2016;125:339-57.

10 Gilman R, Huebner S. A review of life satisfaction research with children and adolescents. Sch Psychol Q. 2003;18:192-205.

11 Gilman R. The relationship between life satisfaction, social interest, and frequency of extracurricular activities among adolescent students. J Youth Adolesc. 2001;30:749-67.

12 Antaramian SP, Kamble SV, Huebner ES. Life satisfaction and coping in Hindu adolescents in India. J Happiness Stud. 2008;17: 1703-17.

13 Antaramian SP, Scott Huebner E, Hills KJ, Valois RF. A dual-factor model of mental health: toward a more comprehensive understanding of youth functioning. Am J Orthopsychiatry. 2010;80:462-72. 
14 Antaramian SP, Kamble SV, Huebner ES. Life satisfaction and coping in Hindu adolescents in India. J Happiness Stud. 2015;17: 1703-17.

15 Lewis AD, Huebner ES, Malone PS, Valois RF. Life satisfaction and student engagement in adolescents. J Youth Adolesc. 2011;40: 249-62.

16 Bifulco A, Moran PM, Baines R, Bunn A, Stanford K. Exploring psychological abuse in childhood: II. Association with other abuse and adult clinical depression. Bull Menninger Clin. 2001;66:241-58.

17 Chapman DP, Whitfield CL, Felitti VJ, Dube SR, Edwars VL, Anda RF. Adverse childhood experiences and the risk of depressive disorders in adulthood. J Affect Disord. 2004;82:217-25.

$18 \mathrm{Lu} \mathrm{W}$, Mueser KT, Rosenberg SD, Jankowski MK. Correlates of adverse childhood experiences among adults with severe mood disorders. Psychiatr Serv. 2008;59:1018-26.

19 Konradt CE, Jansen K, Magalhães PVS, Pinheiro RT, Kapczinski FP, Silva RA, Souza LDM. Trauma precoce e transtornos de humor em jovens. Rev Psiquiatr Clin. 2013;40:93-6.

20 Cecil CA, Viding E, Fearon P, Glaser D, McCrory EJ. Disentangling the mental health impact of child abuse and neglect. Child Abuse Negl. 2017;63:106-19.

21 de Oliveira IR, Matos-Ragazzo AC, Zhang Y, Vasconcelos NM, Velasquez ML, Reis D, et al. Disentangling the mental health impact of childhood abuse and neglect: a replication and extension study in a Brazilian sample of high-risk youth. Child Abuse Negl. 2018;80: 312-23.

22 Metel D, Arciszewsk A, Daren A, Frydecka D, Cechnicki A, Gaweda L. Resilience and cognitive biases mediate the relationship between early exposure to traumatic life events and depressive symptoms in young adults. J Affect Disord. 2019;254:26-33.

23 Klumparendt A, Nelson J, Barengrüggel J, Ehring T. Associations between childhood maltreatment and adult depression: a mediation analysis. BMC Psychiatry. 2019;19:36.

24 Zhao J, Peng X, Chao X, Xiang Y. Childhood maltreatment influences mental symptoms: the mediating roles of emotional intelligence and social support. Front Psychiatry. 2019;10:415.

25 Sperry DM, Widow CS. Child abuse and neglect, social support, and psychopathology in adulthood: a prospective investigation. Child Abuse Negl. 2013;37:415-25.

26 Cameranesi M, Lix LM, Piotrowski CC. Linking a history of childhood abuse to adult health among Canadians: a structural equation modelling analysis. Int J Environ Res Public Health. 2019 May 31;16(11). pii: E1942. doi: 10.3390/ijerph16111942.

27 Zhou J, Feng L, Hu C, Pao C, Xiao L, Wang G. Associations among depressive symptoms, childhood abuse, neuroticism, social support and coping style in the population covering general adults, depressed patients, bipolar disorder patients, and high risk population for depression. Front Psychol. 2019;10:1321.

28 Veronese G, Pepe A, Jaradah A, Al Muranak F, Hamdouna H. Modelling life satisfaction and adjustment to trauma in children exposed to ongoing military violence: an exploratory study in Palestine. Child Abuse Negl. 2017;63:61-72.
29 Suldo SM, Huebner ES. Does life satisfaction moderate the effects of stressful life events on psychopathological behavior during adolescence? Sch Psychol Q. 2004;19:93-105.

30 de Oliveira IR, Matos AC, Ribeiro MG, Velasquez ML. Changing adolescent dysfunctional core beliefs with Group Trial-Based Cognitive Training (G-TBCT): proposal of a preventative approach in schools. Curr Psychiatry Rev. 2016;12:65-78.

31 Gomes LP, Baron E, Albornoz ACG, Borsa JC. Inventário de depressão infantil (CDI): uma revisão de artigos científicos brasileiros. Contextos Clinic. 2013;6:95-105.

32 Gouveia VV, Barbosa GA, Almeida HJF, Gaião AA. Inventário de depressão infantil - CDI: estudo de adaptação com escolares de João Pessoa. J Bras Psiquiatr. 1995;44:345-9.

33 Grassi-Oliveira R, Stein LM, Pezzi JC. Tradução e validação de conteúdo da versão em português do Child Trauma Questionnaire. Revista de Saúde Pública. 2006;40:249-55.

34 Barros LP, Petribú K, Sougey E, Huebner ES. Multidimensional students' life satisfaction scale: translation into Brazilian Portuguese and cross-cultural adaptation. Braz J Psychiatry. 2014;36:102-3.

35 Baron RM, Kenny DA. The moderator-mediator variable distinction in social psychological research: conceptual, strategic, and statistical considerations. J Pers Soc Psychol. 1986;51:1173-82.

36 Pilati R, Laros JA. Modelos de equações estruturais em psicologia: conceitos e aplicações. Psic Teor Pesq. 2007;23:205-16.

37 Bolger KE, Patterson CJ. Pathways from child maltreatment to internalizing problems: perceptions of control as mediators and moderators. Dev Psychopathol. 2001;13:913-40.

38 Keiley MK, Howe TR, Dodge KA, Bates JE, Pettit GS. The timing of child physical maltreatment: A cross-domain growth analysis of impact on adolescent externalizing and internalizing problems. Dev Psychopathol. 2001;13:891-912.

39 Egeland B, Yates T, Carmody KA, van Dulmen MH. The long-term consequences of maltreatment in the early years: a developmental pathway model to antisocial behavior. Child Serv. 2002;5:249-60.

40 Kim KJ, Conger RD, Elder GH Jr, Lorenz FO. Reciprocal influences between stressful life events and adolescent internalizing and externalizing problems. Child Dev. 2003;74:127-43.

41 Cicchetti D, Rogosch FA, Gunnar MR, Toth SL. The differential impacts of early physical and sexual abuse and internalizing problems on daytime cortisol rhythm in school aged children. Child Dev. 2010;81:252-69.

42 Tanaka M, Wekerle C, Schmuck ML, Paglia-Boak A; MAP Research Team. The linkages among childhood maltreatment, adolescent mental health, and self-compassion in child welfare adolescents. Child Abuse Negl. 2011;35:887-98.

43 Harkness KL, Bagby MR, Kennedy SH. Childhood maltreatment and differential treatment response and recurrence in adult major depressive disorder. J Consult Clin Psychol. 2012;80:342-53.

44 World Health Organization (WHO). Maternal, newborn, child and adolescent health: adolescents and mental health [Internet]. 2017 (cited 2017 Jun 16). www.who.int/maternal_child_adolescent/topics/ adolescence/mental_health/en/ 